\title{
Adherence to dietary recommendations is not associated with depression in two Swiss population-based samples
}

Aline Richarda, Sabine Rohrmann ${ }^{\mathrm{a}}$, Caroline L. Vandeleurb, Aurélie M. Lasserreb, MariePierre F. Strippolib, Monika Eichholzera, Jennifer Glaus ${ }^{\mathrm{b}, \mathrm{d}}$, Pedro Marques-Vidalc, Peter Vollenweiderc, Martin Preisigb

a Epidemiology, Biostatistics and Prevention Institute, University of Zurich, Zurich, Switzerland

b Centre for Research in Psychiatric Epidemiology and Psychopathology, Department of Psychiatry, Lausanne university hospital, Prilly, Switzerland

c Department of internal medicine, internal medicine, Lausanne university hospital, Lausanne, Switzerland

d Genetic Epidemiology Research Branch, Intramural Research Program, National Institute of Mental Health, Bethesda, MD, USA

*Corresponding author:

Sabine Rohrmann

University of Zurich; Epidemiology, Biostatistics and Prevention Institute

Division of Chronic Disease Epidemiology

Hirschengraben 84

CH-8001 Zürich

phone: +41446345256

e-mail: Sabine Rohrmann@uzh.ch 


\begin{abstract}
Little is known about adherence to dietary recommendations and depression. Furthermore, dietary habits may differ among depression subtypes, which has not been evaluated previously. Two population-based Swiss studies, including 3,620 individuals from PsyCoLaus and 11,032 individuals from the Swiss Health Survey 2012 (SHS), were used to examine the associations between adherence to common dietary guidelines and odds of depressive disorders. In both studies, depression was assessed by validated instruments. Adherence to dietary recommendations were assessed by a semiquantitative food frequency questionnaire (PsyCoLaus) and by single item questions (SHS). Logistic regression analyses were used to assess the association of adhering to dietary recommendations with depression. For the analyses of diet with depression subtypes maximum-likelihood multinomial (polytomous) logistic regression analyses were conducted. No association of adherence to dietary recommendations with current major depressive disorder (MDD) was observed in any of the two study populations except for adherence to fish consumption, which was positively associated with MDD in the SHS. For depression subtypes, statistically significantly positive associations of vegetable consumption and adherence to the 5-a-day recommendation with current unspecified and current melancholic MDD were found. In conclusion, we don't see consistent associations between adherence to dietary recommendations and MDD or subtypes of depression.
\end{abstract}

Keywords: depression, depression subtypes, diet, dietary recommendations 


\section{Introduction}

Unhealthy diet and depression are major public health concerns, which impact morbidity and even mortality (Mortality and Causes of Death, 2015; Whiteford et al., 2013). In recent years, the complex associations of diet and depression have raised great interest. Healthy diet has been described as a protective factor for the occurrence and recurrence of depressive disorders (Lai et al., 2014; Rahe et al., 2014). First, research focused on single nutrients, then, concentrated on single dietary components and dietary patterns, such as the Mediterranean diet. In summary, there are indications that unhealthy dietary patterns may affect the onset of depression (Quirk et al., 2013; Rahe et al., 2014) and it has been shown previously that a large number of bioactive compounds (e.g. ghrelin, leptin, IGF-1, anti-oxidants) may act as mediators of particular foods and affect mental health (Lang et al., 2015; Miller et al., 2000).

To the best of our knowledge, only one longitudinal study and two cross-sectional studies investigated the associations between existing dietary recommendations and mental health (Akbaraly et al., 2013; Jacka et al., 2012; Richard et al., 2015). Dietary recommendations for single dietary components, such as fruit and vegetables, fish, and meat, are broadly promoted in many countries in order to enhance an individual's physical health. The recommendations vary among different countries, but are broadly known and promoted by national nutrition societies, but also by the food industry. Definitions of these recommendations (e.g. 5-a-day for fruit and vegetables) were derived from the WHO Global Strategy on Diet, Physical Activity and Health (World Health Organisation, 2004). Healthy fruit and vegetable consumption, known as the 5-aday recommendation (i.e. daily consumption of at least 3 portions of vegetables and 2 portions of fruit), is the best-known dietary campaign. It was implemented in the 1990s by the National Cancer Institute in the U.S, and started in Switzerland in 2001 recommended by the Swiss Nutrition Society (Schweizerische Gesellschaft für Ernährung SGE, 2013). The recommendation of consuming meat less than 5 times a week is similar in Switzerland as mentioned in the World Cancer Research Fund (WCRF), which examined lifestyle factors that affect different types of cancer (WCRF and AICR, 2009). The origin of the Swiss recommendation of consuming fish at least once a week is unclear. All these recommendations are based on research results that examine physical health, and not mental health, as an outcome. 
In Switzerland, dietary recommendations are based on the Swiss Nutrition Society (Schweizerische Gesellschaft für Ernährung SGE, 2013). Compliance with dietary recommendations among adults in Switzerland is low (de Abreu et al., 2013).

Thus, it is worthwhile not only to look at associations of diet with physical health, but also with mental health, which could then lead to the proposition of adhering to dietary recommendations if such a link were shown. In our previous research, we have shown significant inverse associations of the adherence to the 5-a-day recommendation of fruit and vegetables consumption with psychological distress (Richard et al., 2015), which may be an indicator of depression (Bale, 2006).

The aim of our study was to estimate the associations between adherence to several dietary recommendations and depression in Switzerland, in addition to look even more closely at depression by including subtypes of depression. It is important to assess diet quality across subtypes because depression subtypes have previously shown different associations with BMI, obesity indicators and cardiovascular risk factors (Lasserre et al., 2016).

Hence, due to the lack of knowledge, we first examined the associations of adhering to a variety of dietary recommendations - such as fruit, vegetables, meat and fish consumption - with depression. The possible role of milk and dairy products in depressive symptoms has not received much attention in the literature and the findings of previous studies have been inconsistent (Aihara et al., 2011; Meyer et al., 2013; Miyake et al., 2016; Pasco et al., 2015). Therefore, we did not include this food group into our analyses.

Second, given the increasing awareness of the heterogeneity of major depressive disorder in terms of symptom manifestations, course and response to pharmacological treatment (Antonijevic, 2006; Ghaemi and Vohringer, 2011; Halbreich, 2006; Klein, 2008), we additionally evaluated clinically diagnosed subtypes of depression because dietary habits may differ among depression subtypes.

To enhance the representativeness for Switzerland to include different types of assessment of diet and depression, we included two different population-based Swiss datasets. The first one, from the CoLaus/PsyCoLaus study in Lausanne, provides dietary information from a food-frequency questionnaire and information about major 
depressive disorders (MDD) based on a semi-structured interview, which also allowed to define subtypes of depression. The second one is derived from the Swiss Health Survey (SHS), a population-based study with approximately 20,000 participants and self-reported data on food consumption and depression.

\section{Methods}

\subsection{Study population}

The data of the present paper stemmed from CoLaus/PsyCoLaus (Firmann et al., 2008; Preisig et al., 2009), a prospective cohort study designed to study mental disorders and cardiovascular risk factors in the community. The sample was randomly selected from the residents of the city of Lausanne (Switzerland) from 2003 to 2006 according to the civil register. Detailed descriptions of the study design and sampling procedures have been reported elsewhere (Preisig et al., 2009). The CoLaus/PsyCoLaus study was approved by the Institutional Ethics Committee of the University of Lausanne and all participants gave written informed consent.

For the present analysis we used data from the first follow-up, which includes information on dietary habits. This follow-up was conducted from 2009 to 2012. Among the 6,733 subjects who participated in the physical baseline investigation 3,670 aged between 40 and 80 years also participated in the psychiatric follow-up evaluation and completed the semi-quantitative food frequency questionnaire. For the assessment of the association between diet and depression we excluded participants with missing information on depression status $(n=2)$ or confounders $(n=48)$ resulting in a final sample of 3,620 individuals.

The Swiss Health Survey (SHS) is conducted every 5 years to collect information on health status, several lifestyle and demographic factors and is a cross-sectional, nationwide survey, which included 21,597 participants in 2012. It used a stratified random sampling technique based on registries of inhabitants, including individuals aged 15 years or older who lived in a private household. A computer-assisted telephone interview followed by a written questionnaire (paper or online) was provided upon approval from the participants (Swiss Federal Statistical Office). The SHS was conducted 
by the Swiss Federal Bureau of Statistics and does not require formal approval by an ethics committee. This data collection is specifically permitted under Swiss law (SR 431.012.1 and SR 431.112.1).

In the SHS from 2012, 11,230 individuals aged 40+ years completed the written Patient Health Questionnaire (PHQ-9). After excluding individuals with missing information on dietary factors $(n=60)$ and confounders $(n=138)$ our final SHS dataset consisted of 11,032 individuals.

To our knowledge, the SHS and the PsyCoLaus study are two of the largest populationbased studies in Switzerland with data on both depression and diet quality.

\subsection{Dietary intake}

In CoLaus/PsyCoLaus, a semi-quantitative food frequency questionnaire including about 90 food items and three different serving portions for each item was used. It assessed eating behaviors for 4 weeks prior to data collection and was developed and validated in the general adult population of Geneva, Switzerland (Morabia et al., 1994).

In the SHS eating behavior was assessed with questions on the usual frequency and number of portions consumed. For both fruit and vegetables, two questions were asked. The first question was related to frequency: "On how many days a week do you usually eat fruit or drink fruit juices?" or "On how many days a week do you usually eat vegetables or salad or drink vegetable juices (potatoes do not count)? Answers were coded as "less", "rarely", “1", “2", ... to "7" times a week. The second question was related to the number of portions consumed: "And how many portions of fruit or fruit juices do you consume on average per day? One portion would be as big as a handful (i.e. 1 apple, 1 pear). For juice it is about $2 \mathrm{dl}$ " and "And how many portions of vegetables, salad or vegetable juices do you consume daily on average? One portion would be as big as a handful (or about 1 tomato, 1 big carrot). For juice it is about $2 \mathrm{dl}$ ". The second question was only asked if the first question was positive for a frequency of at least " 5 times a week" and answers were coded into "less than 1 portion", and "1", "2", "3", "4" and "5 portions or more". In relation to meat and fish consumption the following questions were asked: "On how many days a week do you eat fish on average?" and "On how many 
days a week do you usually eat meat or meat products?" Answers were coded as "less", "rarely", "1", "2", ... to "7" times a week.

Consumption frequencies reported by the study participants were converted into daily frequency and then the food items were dichotomized according to the dietary recommendations from the Swiss Society of Nutrition (Schweizerische Gesellschaft für Ernährung SGE, 2013). Adhering to the dietary recommendations was defined as follows: at least 2 portions of fruit or fruit juice per day, at least 3 portions of vegetables per day, at least 3 portions of vegetables and 2 portions of fruit per day (5-a-day), less than 5 portions of meat or red meat per week (CoLaus/PsyCoLaus)/ less than 5 times a week (SHS), and at least one portion of fish per week (CoLaus/PsyCoLaus)/ at least once a week (SHS).

\subsection{Outcome measures}

In CoLaus/PsyCoLaus, depression was assessed using the semi-structured Diagnostic Interview for Genetic Studies (DIGS) (Nurnberger et al., 1994; Preisig et al., 1999), where current, remitted and lifetime major depressive disorder (MDD) were diagnosed according to the DSM-IV criteria. The French translation of the DIGS was used (Leboyer et al., 1995), which has shown excellent inter-rater and sufficient test-retest reliability in terms of kappa and Yule's Y coefficients for major mood and psychotic disorders (Preisig et al., 1999). The DIGS allows for the categorization of lifetime MDD into four subtypes (Angst et al., 2007) 1) MDD with at least one atypical and one melancholic episode (combined type); 2) MDD with at least one atypical (but no melancholic) episode; 3) MDD with at least one melancholic (but no atypical) episode; and 4) MDD with neither atypical nor melancholic episodes (unspecified type). For the definitions of MDD subtypes, we used the DSM-IV specifiers. Considering the ongoing controversies related to the atypical specifier (Angst et al., 2002; Matza et al., 2003; Parker et al., 2002), we used the DSM-IV criteria for atypical depression features in a non-hierarchical way (Angst et al., 2002). Given that we adjust for body mass index (BMI), we only applied the appetite part of the DSM-IV criterion of atypical depression requiring either increased appetite or weight gain.

In the SHS of 2012, depression was assessed using the Patient Health Questionnaire (PHQ-9). This short screening questionnaire is a valid tool to assess depression by 
scoring on each of the 9 DSM-IV criteria for major depressive episodes and is broadly used in both practice and research (Kroenke et al., 2001; Manea et al., 2012). Symptoms over the last two weeks were assessed. From a possible total score of 27 the cut-off point of $\geq 10$ has shown a sensitivity of $88 \%$ and a specificity of $88 \%$ for the diagnosis of current major depression (Kroenke et al., 2001; Manea et al., 2012). Thus, we dichotomized a participant's PHQ-9 score into $<10$ (no depression) and $\geq 10$ (depression).

\subsection{Covariates}

We used a priori defined covariates according to the literature (Lai et al., 2014). Age, sex, body mass index (BMI), socio-economic status (SES) and educational level, alcohol consumption, smoking status, and physical activity were included (for both CoLaus/PsyColaus and the SHS). BMI was defined as weight/height ${ }^{2}$. SES was determined according to the Hollingshead scale (Hollingshead AB.) and educational level was divided into low (compulsory education or less), middle (secondary education) and high (tertiary education). Alcohol consumption was categorized into non-drinkers, low risk (1 to 13 drinks per week), medium to high risk (14 to 34 drinks per week), and very high risk (35+ drinks per week) in CoLaus/PsyCoLaus, and as $\leq 20 \mathrm{~g}$ ethanol per day for women and $\leq 40 \mathrm{~g}$ for men vs. $>20 \mathrm{~g}$ and $>40 \mathrm{~g}$, respectively, in the SHS (U.S. Department of Agriculture and U.S. Department of Health and Human Services, 2010). Never, former and current smokers were differentiated. In CoLaus, participants were considered to be physically active if they reported physical activity for at least 20 minutes twice a week and in the SHS if they reported at least 150 minutes of exercise per week (BASPO, 2013). Energy intake was computed based on the French CIQUAL food composition table, which was linked to the FFQ used in Psycolaus.

\subsection{Statistical analyses}

Statistical analyses were performed with the Stata software version 13.1 (Stata Corporation, College Station, TX, USA). Descriptive characteristics of the study samples were stratified by depression status and described by means \pm SD and percentages. Results of the SHS were weighted. Weights from the written questionnaire were provided by the Swiss Federal Statistical Office (SFSO), which allows for comparison 
with the permanent Swiss population in 2012 with regard to sex, age, geographic region and nationality (Swiss vs. others). For CoLaus/PsyCoLaus, the sample has been shown to only slightly differ from the general population of Lausanne in age but not in sex. Therefore weighting is not needed for analyses (Preisig et al., 2009).

Logistic regression analyses were used to assess the associations between adhering to the dietary recommendations and depression as a dichotomous outcome and computed in terms of Odds Ratios (OR) and 95\% confidence intervals (CI). For CoLaus/PsyCoLaus, remitted depression was excluded from the analyses of the dichotomized outcomes of "no MDD" and "current MDD". Moreover, for the analyses of the dietary recommendations with MDD subtypes in CoLaus/PsyCoLaus, we conducted maximumlikelihood multinomial (polytomous) logistic regression analyses with "no MDD" as the reference. To enhance comprehensibility results were expressed in terms of OR instead of using the original output of Relative Risk Ratio (RRR). Models computed in sequence were, first adjusted for age- and sex; second, adjusted for all demographic factors, and third, adjusted for all demographic and dietary factors (meat, fruit, vegetables and fish mutually).

\section{Results}

Descriptive characteristics of both study samples are shown in table 1.

In CoLaus/PsyCoLaus, we observed no statistically significant associations of adherence to any dietary recommendations with current MDD (table 2). Additionally adjusting for energy intake did not change the results and neither did comparing lifetime MDD (i.e. remitted and current MDD) with no MDD (both sensitivity analyses in CoLaus/PsyCoLaus; results not shown). In contrast to CoLaus/PsyCoLaus, adhering to the recommendations of fish consumption was positively associated with depression in the SHS (OR 1.28, 95\%CI 1.01-1.63; multivariable adjusted model for demographic and other dietary factors). Other dietary factors were not associated with the likelihood of depression in the SHS after full adjustments.

Analysis of the association of adhering to dietary recommendations with MDD subtypes from the CoLaus/PsyCoLaus data revealed no statistically significant associations 
(results not shown). But as shown in table 3, by further stratifying MDD subtypes into current and remitted MDD, we found statistically significantly positive associations of vegetable consumption and adherence to the 5-a-day recommendation with the likelihood of suffering from current unspecified and current melancholic MDD (OR 2.09, 95\% CI 1.08-4.06 and OR 2.51, 95\% CI 1.21-5.21, respectively; multivariable adjusted for demographic and other dietary factors). Similarly, vegetable consumption was associated with current melancholic MDD (OR 2.44, 95\% CI 1.27-4.70).

\section{Discussion}

In our study, we did not find any association of adherence to dietary recommendations with current depression in either of the two study populations except for adherence to fish consumption, which was positively associated with depression in the SHS contrary to our expectations. For subtypes of depression, we found positive associations of adhering to vegetables and 5-a-day recommendations with current unspecified and current melancholic depression.

Furthermore, we found differences in prevalences of depression between the SHS and PsyCoLaus, which are most probably explained by the fact that in the SHS symptoms of major depression over the last two weeks were assessed. In contrast, Psycholaus assessed current, remitted and lifetime major depressive disorders. However, the lifetime prevalence of depressive disorders in our PsyCoLaus data (about $45 \%$ in the first follow-up) is higher than the typical range of lifetime estimates according to recent studies using interviews based on DSM-IV criteria. The high prevalence of depressive disorders in PsyCoLaus is at least partially be explained by the particular features of the sample and the diagnostic instrument. Study participants were recruited in an urban area and there is evidence for high prevalence of any psychiatric disorder including depressive disorders in urban areas (e.g. NEMESIS) (Peen et al., 2007). In addition, the characteristics of the DIGS interview further favored the diagnoses of depressive disorders. Second, the interview was administered by trained psychologists in a face-toface setting, which also favours recall compared to completion of a rating scale. The semi-structured nature of the DIGS was likely to provide higher prevalence estimates than, for example, the fully structured Composite International Diagnostic Interview 
(CIDI), which was applied in most previous community surveys. Indeed, research that compared the fully structured Diagnostic Interview Schedule (DIS), designed similarly to the CIDI for lay interviewers, with the semi-structured Schedule for Clinical Assessment in Neuropsychiatry (SCAN) found twice as high rates of MDD according to the latter interview conducted by mental health professionals (Eaton et al., 2000). It has been suggested that structured interviews may even under-estimate the prevalence of depression in community samples (Kruijshaar et al., 2005).

In contrast, information on depression in the SHS was collected using only the self-rated PHQ. Although this short screening questionnaire is a valid tool to assess depression by scoring on each of the 9 DSM-IV criteria for major depressive episodes and is broadly used in both practice and research (Kroenke et al., 2001; Manea et al., 2012), it only assesses symptoms over the previous two weeks. In this respect, this is more of a measure of current depression and prevalence rates of current episodes are generally much lower than lifetime estimates.

Our new findings focusing on dietary recommendations can be compared in regard to a variety of studies, which examined the associations of diet with depression (Lai et al., 2014; Murakami and Sasaki, 2010; Quirk et al., 2013; Rahe et al., 2014; Sanhueza et al., 2013). Limited evidence between dietary patterns and depression was found in two reviews, such as an inverse association of western diet with depression, and a positive association of Mediterranean diet with depression (Quirk et al., 2013; Rahe et al., 2014). One review concluded that a high intake of fruit, vegetables, fish, and whole grains, but not a western dietary pattern, was associated with a lower risk of depression (Lai et al., 2014), but another systematic review of observational studies (10 prospective, 23 crosssectional, and 1 case-control study) came to the conclusion that an association between dietary habits and depression was mostly not present, and that this may be due to methodological limitations (Murakami and Sasaki, 2010). In contrast, a systematic review of randomized controlled trials observed improved symptoms in depressed individuals after dietary interventions (Opie et al., 2015).

Less is known with respect to the adherence to dietary recommendations. One prospective study found an association between adherence (summarized from different foods into a score) and a reduced likelihood of developing recurrent depression after 5 
years in women, but not in men (Akbaraly et al., 2013). In contrast to pre-defined dietary scores, another approach to assess the association of diet with depression has been widely used by extracting factors from a food-frequency questionnaire and then deriving dietary patterns that are associated with depression. In a cross-sectional study, a healthy dietary pattern, i.e. consumption of high fresh vegetable, cooked vegetable, fruit, whole-grain bread, poultry, berry, low-fat cheese and fish, was associated with lower depression prevalence (Ruusunen et al., 2014). In the same study this "prudent" pattern was inversely associated with the risk of suffering from depression after 16.5 years of follow-up. A further study in middle-aged Australian women identified healthy dietary patterns from factor analysis, in which the "Mediterranean-style" dietary pattern was associated with lower incident depression after 3 years (Rienks et al., 2013). One important part of a Mediterranean diet is a high intake of fruit and vegetables (Ferrari and Rapezzi, 2011).

To our knowledge, there is no study that looked at the association of adherence to the 5a-day recommendation of fruit and vegetable consumption with depression. In a previous analysis of the SHS data, we showed that adhering to these recommendations was associated with lower psychological distress (Richard et al., 2015).

There is good evidence that high red and processed meat consumption is associated with higher physical morbidity and mortality in prospective studies (Bouvard et al., 2015; Larsson and Orsini, 2014). However, an Australian cross-sectional study observed that low or no meat consumption was associated with MDD (Baines et al., 2007) and another cross-sectional study in Australian women reported that adhering to the dietary recommendation for red meat was positively associated with depression compared to not adhering to these recommendations (Jacka et al., 2012).

The association of fish consumption with depression has been examined widely for years (Hibbeln, 1998) and results provide some evidence for a protective effect of fish consumption on depression, as observed in a recent meta-analysis including cohort studies (Li et al., 2015). In our study, we found no associations in CoLaus/PsyCoLaus, but a positive association of fish consumption and depression in the SHS. Nevertheless, this association is only borderline significant, and thus, may be due to chance. On the other hand, fish consumption may be associated with a higher risk of depression due to contamination with heavy metals such as methylmercury or contamination with dioxin. 
There is some evidence that high exposure to mercury may increase the risk of psychiatric symptoms, but in relation to low level mercury exposure and depression, human studies have not yielded consistent results (Ng et al., 2013). Concerning dioxin exposure and depression the evidence of the very limited number of studies is inconsistent (Morse et al., 2012). Furthermore, in the SHS there is no information about the kind of fish the participants consumed, thus their exposure to contaminants in fish cannot be estimated. The kind of fish is of importance, because methylmercury for example enters aquatic food chains, starting with uptake into plankton and eventually attaining its highest concentration in large, predatory fish. It accumulates throughout the lifetime of the fish. Thus the highest concentrations are found in the longest lived, top predatory fish such as shark and swordfish in the oceans and pike and bass in freshwater. Thus, information on the kind of fish but also of the exact amount consumed is of importance to estimate exposure to contaminants (Clarkson, 1993). Such data are missing in the SHS.

Based on the results of the above mentioned reviews, we hypothesized that the lack of association between adhering to dietary recommendations and MDD may be due to the variety of depression phenotypes which are characterized - amongst other factors - by different eating behaviors (Harald and Gordon, 2012). Thus, diet might be associated with some, but not all, subtypes of depression. This was partly shown in the present analyses of CoLaus/PsyCoLaus data, as adherence to the vegetable- and the 5-a-day recommendations were associated with current unspecified and current melancholic MDD. Core symptoms of melancholic MDD are psychomotor change, loss of pleasure, and lack of mood reactivity, loss of appetite and loss of weight as a consequence.

We hypothesize that adhering to the 5-a-day recommendations in current melancholic depression is associated with weight loss, because of the healthier eating behavior. This hypothesis is supported by a recent CoLaus/PsyCoLaus analysis, which reported low body weight in individuals with melancholic MDD cross-sectionally (Glaus et al., 2013), and by another cross-sectional study that found the highest dietary quality scores in patients with melancholic depression (Rahe et al., 2015). However, another CoLaus/PsyCoLaus analysis observed that individuals with remitted melancholic MDD had even lower BMI compared to subjects with other depressive disorders at baseline (Lasserre et al., 2014), and a longitudinal analysis within CoLaus/PsyCoLaus showed 
that low BMI preceded the onset of MDD in general and also of melancholic MDD. The participants with melancholic MDD had decreased appetite and lost weight during their depressive episodes although their BMI was comparable with that of the non-depressed after the depressive episode (Lasserre et al., 2014). This could imply that depression changes dietary habits. In this context, it is of interest to note that Rahe and colleagues (Rahe et al., 2015) found in their German cross-sectional study that patients with melancholic depression had significantly higher diet quality scores than controls from the general population. The diet quality score reflected the adherence to nutritional recommendations on a well-balanced diet including consumption of fruit and vegetables, whole grain products, fish, meat etc. Furthermore, patients with melancholic depression showed the highest, and patients with atypical depression the lowest diet quality score, with a higher consumption of the food groups "chocolate", cake/pastries/biscuits" in the latter group. Rahe et al. concluded that patients with melancholic depression seem to consume less of these low-quality foods, which in turn has positive impact on their actual diet quality (Rahe et al., 2015). Even though in both studies it was not possible to clarify why patients with melancholic depression ate a healthier diet, our findings and the results of the study by Rahe et al. go in the same direction and thus might not just be chance findings. Hence, reverse causation might also be an explanation for our findings. However, the positive association of adherence to the 5-a-day recommendations and current unspecified MDD is novel and has not been examined in other studies. This needs to be tested in prospective studies.

\subsection{Strengths and limitations}

This study provides the opportunity to compare results from two population-based Swiss studies, which had different strengths concerning the study design. In summary, CoLaus/PsyCoLaus provided the more methodologically sound instruments for assessing exposure and outcome variables, whereas the SHS contributed to a broader population-based approach, with a higher generalizability of findings for Switzerland. In PsyCoLaus there is an optimal measure of depression using a semi-structured interview administered by trained psychologists, contrary to the bulk of research which measured depression using rating scales. In addition, the interview data allowed to subtype MDD which is not possible using rating scales. Moreover, PsyCoLaus used a validated 
relatively comprehensive scale for the assessment of diet quality. Also adjustment for BMI was done using somatic measures of weight and height taken by nurses and was not based on self-reported BMI.

For the explanatory dietary variables two approaches were used: a semi-quantitative food frequency questionnaire in CoLaus/PsyCoLaus and single questions in the SHS. Thus, results of the associations of adhering to dietary recommendations and depression that were concordant between CoLaus/PsyCoLaus and the SHS provide a good estimate for these associations, which were basically null, for Switzerland. This was true for lifetime depression (CoLaus/PsyCoLaus) as well as for depression during the past two weeks (SHS). However, our conclusions are limited by the cross-sectional design of both studies and, thus, reversed causality should also be considered. Furthermore, residual confounding cannot be excluded.

A further strength is the inclusion of depression subtypes to clarify possible associations of diet with depression, which has rarely been examined to date (Li et al., 2015). On the other hand, a limitation of this approach is the low sample sizes in subgroups, such as low adherence to dietary recommendations in some the subtypes of depression (de Abreu et al., 2013; Schweizerische Gesellschaft für Ernährung SGE, 2013). Thus, our negative findings might partly be explained by the lack of statistical power. A further strength was the similar controlling for potential confounders in both studies, which allowed us to present multivariable adjusted results from both studies in parallel.

Dietary patterns are often assessed quite heterogeneously and results of these studies are contradictory. Therefore, the assessment of existing dietary recommendations in contrast to dietary patterns might be more meaningful.

In conclusion, we did not observe any meaningful associations of adhering to dietary recommendations with depression in Switzerland in two population-based study types; only fish consumption turned out to be positively associated with MDD in the SHS although this was only marginally significant. For subtypes of depression, we found positive associations of adhering to vegetables and 5-a-day consumption with current unspecified and current melancholic depression. As little is known about diet and 
subtypes of depression further analyses are needed, in particular using prospective studies to eliminate the effect of reverse causation.

\section{Acknowledgements}

The authors thank the Swiss Federal Office of Statistics for permission to use the data of the 2012 Swiss Health Survey.

\section{Role of funding sources for CoLaus/PsyCoLaus}

The CoLaus/PsyCoLaus study was and is supported by research grants from GlaxoSmithKline, the Faculty of Biology and Medicine of Lausanne, and the Swiss National Science Foundation (grants 3200B0-105993, 3200B0-118308, 33CSCO122661, 33CS30-139468 and 33CS30-148401). The funders had no role in the design of the study; the collection, management, analysis, and interpretation of the data; the preparation, review or approval of the manuscript; or the decision to submit the manuscript for publication.

\section{Conflict of interest}

The authors declare that there are no financial or personal relationships with other people or organizations that could inappropriately influence the work reported or the conclusions, implications, or opinions stated.

\section{Authors' contributions}

AR, MP and SR designed the paper and the analyses. AR performed the statistical analyses and wrote the manuscript. SR and MP supervised the study. All authors discussed the results and implications and commented on the manuscript at all stages and have approved the final manuscript. 


\section{References}

Aihara, Y., Minai, J., Aoyama, A., Shimanouchi, S., 2011. Depressive symptoms and past lifestyle among Japanese elderly people. Community Ment Health J 47 (2), 186193.

Akbaraly, T.N., Sabia, S., Shipley, M.J., Batty, G.D., Kivimaki, M., 2013. Adherence to healthy dietary guidelines and future depressive symptoms: evidence for sex differentials in the Whitehall II study. Am J Clin Nutr 97 (2), 419-427.

Angst, J., Gamma, A., Benazzi, F., Ajdacic, V., Rossler, W., 2007. Melancholia and atypical depression in the Zurich study: epidemiology, clinical characteristics, course, comorbidity and personality. Acta Psychiatr Scand Suppl(433), 72-84.

Angst, J., Gamma, A., Sellaro, R., Zhang, H., Merikangas, K., 2002. Toward validation of atypical depression in the community: results of the Zurich cohort study. J Affect Disord 72 (2), 125-138.

Antonijevic, I.A., 2006. Depressive disorders -- is it time to endorse different pathophysiologies? Psychoneuroendocrinology 31 (1), 1-15.

Baines, S., Powers, J., Brown, W.J., 2007. How does the health and well-being of young Australian vegetarian and semi-vegetarian women compare with nonvegetarians? Public Health Nutr 10 (5), 436-442.

Bale, T.L., 2006. Stress sensitivity and the development of affective disorders. Horm Behav 50 (4), 529-533.

BASPO, 2013. Gesundheitswirksame Bewegung. Grundlagendokument., Magglingen.

Bouvard, V., Loomis, D., Guyton, K.Z., Grosse, Y., Ghissassi, F.E., Benbrahim-Tallaa, L., Guha, N., Mattock, H., Straif, K., International Agency for Research on Cancer Monograph Working, G., 2015. Carcinogenicity of consumption of red and processed meat. Lancet Oncol 16 (16), 1599-1600.

Clarkson, T.W., 1993. Mercury: major issues in environmental health. Environ Health Perspect 100, 31-38.

de Abreu, D., Guessous, I., Vaucher, J., Preisig, M., Waeber, G., Vollenweider, P., MarquesVidal, P., 2013. Low compliance with dietary recommendations for food intake among adults. Clin Nutr 32 (5), 783-788.

Eaton, W.W., Neufeld, K., Chen, L.S., Cai, G., 2000. A comparison of self-report and clinical diagnostic interviews for depression: diagnostic interview schedule and schedules for clinical assessment in neuropsychiatry in the Baltimore epidemiologic catchment area follow-up. Arch Gen Psychiatry 57 (3), 217-222.

Ferrari, R., Rapezzi, C., 2011. The Mediterranean diet: a cultural journey. Lancet 377 (9779), 1730-1731.

Firmann, M., Mayor, V., Vidal, P.M., Bochud, M., Pecoud, A., Hayoz, D., Paccaud, F., Preisig, M., Song, K.S., Yuan, X., Danoff, T.M., Stirnadel, H.A., Waterworth, D., Mooser, V., Waeber, G., Vollenweider, P., 2008. The CoLaus study: a population-based study to investigate the epidemiology and genetic determinants of cardiovascular risk factors and metabolic syndrome. BMC Cardiovasc Disord 8, 6.

Ghaemi, S.N., Vohringer, P.A., 2011. The heterogeneity of depression: an old debate renewed. Acta Psychiatr Scand 124 (6), 497.

Halbreich, U., 2006. Major depression is not a diagnosis, it is a departure point to differential diagnosis -- clinical and hormonal considerations (a commentary and elaboration on Antonejevic's paper). Psychoneuroendocrinology 31 (1), 16-22; author reply 23-14. 
Harald, B., Gordon, P., 2012. Meta-review of depressive subtyping models. J Affect Disord 139 (2), 126-140.

Hibbeln, J.R., 1998. Fish consumption and major depression. Lancet 351 (9110), 1213.

Hollingshead AB., Four factor index of social status, New Haven: Yale University Press, 1975.

Jacka, F.N., Pasco, J.A., Williams, L.J., Mann, N., Hodge, A., Brazionis, L., Berk, M., 2012. Red meat consumption and mood and anxiety disorders. Psychother Psychosom 81 (3), 196-198.

Klein, D.N., 2008. Classification of depressive disorders in the DSM-V: proposal for a twodimension system. J Abnorm Psychol 117 (3), 552-560.

Kroenke, K., Spitzer, R.L., Williams, J.B., 2001. The PHQ-9: validity of a brief depression severity measure. J Gen Intern Med 16 (9), 606-613.

Kruijshaar, M.E., Barendregt, J., Vos, T., de Graaf, R., Spijker, J., Andrews, G., 2005. Lifetime prevalence estimates of major depression: an indirect estimation method and a quantification of recall bias. Eur J Epidemiol 20 (1), 103-111.

Lai, J.S., Hiles, S., Bisquera, A., Hure, A.J., McEvoy, M., Attia, J., 2014. A systematic review and meta-analysis of dietary patterns and depression in community-dwelling adults. Am J Clin Nutr 99 (1), 181-197.

Lang, U.E., Beglinger, C., Schweinfurth, N., Walter, M., Borgwardt, S., 2015. Nutritional aspects of depression. Cell Physiol Biochem 37 (3), 1029-1043.

Larsson, S.C., Orsini, N., 2014. Red meat and processed meat consumption and all-cause mortality: a meta-analysis. Am J Epidemiol 179 (3), 282-289.

Lasserre, A.M., Strippoli, M.F., Glaus, J., Gholam-Rezaee, M., Vandeleur, C.L., Castelao, E., Marques-Vidal, P., Waeber, G., Vollenweider, P., Preisig, M., 2016. Prospective associations of depression subtypes with cardio-metabolic risk factors in the general population. Mol Psychiatry.

Leboyer, M., Barbe, B., Gorwood, P., Teherani, M., Allilaire, J.F., Preisig, M., Matthey, M.L., Poyetton, V., Ferrero, F., 1995. Interview Diagnostique pour les Etudes Génétiques Paris., INSERM, Paris, France.

Li, F., Liu, X., Zhang, D., 2015. Fish consumption and risk of depression: a meta-analysis. J Epidemiol Community Health.

Manea, L., Gilbody, S., McMillan, D., 2012. Optimal cut-off score for diagnosing depression with the Patient Health Questionnaire (PHQ-9): a meta-analysis. CMAJ 184 (3), E191-196.

Matza, L.S., Revicki, D.A., Davidson, J.R., Stewart, J.W., 2003. Depression with atypical features in the National Comorbidity Survey: classification, description, and consequences. Arch Gen Psychiatry 60 (8), 817-826.

Meyer, B.J., Kolanu, N., Griffiths, D.A., Grounds, B., Howe, P.R., Kreis, I.A., 2013. Food groups and fatty acids associated with self-reported depression: an analysis from the Australian National Nutrition and Health Surveys. Nutrition 29 (7-8), 10421047.

Miller, H.E., Rigelhof, F., Marquart, L., Prakash, A., Kanter, M., 2000. Antioxidant content of whole grain breakfast cereals, fruits and vegetables. J Am Coll Nutr 19 (3 Suppl), 312S-319S.

Miyake, Y., Tanaka, K., Okubo, H., Sasaki, S., Furukawa, S., Arakawa, M., 2016. Milk intake during pregnancy is inversely associated with the risk of postpartum depressive symptoms in Japan: the Kyushu Okinawa Maternal and Child Health Study. Nutr Res 36 (9), 907-913. 
Morabia, A., Bernstein, M., Kumanyika, S., Sorenson, A., Mabiala, I., Prodolliet, B., Rolfo, I., Luong, B.L., 1994. [Development and validation of a semi-quantitative food questionnaire based on a population survey]. Soz Praventivmed 39 (6), 345-369.

Morse, G.S., Duncan, G., Noonan, C., Garroutte, E., Santiago-Rivera, A.L., 2012.

Environmental Toxins and Depression in an American Indian Community. Journal of Indigenous Research 1 (1), 6.

Mortality, G.B.D., Causes of Death, C., 2015. Global, regional, and national age-sex specific all-cause and cause-specific mortality for 240 causes of death, 1990-2013: a systematic analysis for the Global Burden of Disease Study 2013. Lancet 385 (9963), 117-171.

Murakami, K., Sasaki, S., 2010. Dietary intake and depressive symptoms: a systematic review of observational studies. Mol Nutr Food Res 54 (4), 471-488.

Ng, T.H., Mossey, J.M., Lee, B.K., 2013. Total blood mercury levels and depression among adults in the United States: National Health and Nutrition Examination Survey 2005-2008. PLoS One 8 (11), e79339.

Nurnberger, J.I., Jr., Blehar, M.C., Kaufmann, C.A., York-Cooler, C., Simpson, S.G., HarkavyFriedman, J., Severe, J.B., Malaspina, D., Reich, T., 1994. Diagnostic interview for genetic studies. Rationale, unique features, and training. NIMH Genetics Initiative. Arch Gen Psychiatry 51 (11), 849-859; discussion 863-844.

Opie, R.S., O'Neil, A., Itsiopoulos, C., Jacka, F.N., 2015. The impact of whole-of-diet interventions on depression and anxiety: a systematic review of randomised controlled trials. Public Health Nutr 18 (11), 2074-2093.

Parker, G., Roy, K., Mitchell, P., Wilhelm, K., Malhi, G., Hadzi-Pavlovic, D., 2002. Atypical depression: a reappraisal. Am J Psychiatry 159 (9), 1470-1479.

Pasco, J.A., Williams, L.J., Brennan-Olsen, S.L., Berk, M., Jacka, F.N., 2015. Milk consumption and the risk for incident major depressive disorder. Psychother Psychosom 84 (6), 384-386.

Peen, J., Dekker, J., Schoevers, R.A., Have, M.T., de Graaf, R., Beekman, A.T., 2007. Is the prevalence of psychiatric disorders associated with urbanization? Soc Psychiatry Psychiatr Epidemiol 42 (12), 984-989.

Preisig, M., Fenton, B.T., Matthey, M.L., Berney, A., Ferrero, F., 1999. Diagnostic interview for genetic studies (DIGS): inter-rater and test-retest reliability of the French version. Eur Arch Psychiatry Clin Neurosci 249 (4), 174-179.

Preisig, M., Waeber, G., Vollenweider, P., Bovet, P., Rothen, S., Vandeleur, C., Guex, P., Middleton, L., Waterworth, D., Mooser, V., Tozzi, F., Muglia, P., 2009. The PsyCoLaus study: methodology and characteristics of the sample of a populationbased survey on psychiatric disorders and their association with genetic and cardiovascular risk factors. BMC Psychiatry 9, 9.

Quirk, S.E., Williams, L.J., O'Neil, A., Pasco, J.A., Jacka, F.N., Housden, S., Berk, M., Brennan, S.L., 2013. The association between diet quality, dietary patterns and depression in adults: a systematic review. BMC Psychiatry 13, 175.

Rahe, C., Baune, B.T., Unrath, M., Arolt, V., Wellmann, J., Wersching, H., Berger, K., 2015. Associations between depression subtypes, depression severity and diet quality: cross-sectional findings from the BiDirect Study. BMC Psychiatry 15, 38.

Rahe, C., Unrath, M., Berger, K., 2014. Dietary patterns and the risk of depression in adults: a systematic review of observational studies. Eur J Nutr 53 (4), 997-1013.

Richard, A., Rohrmann, S., Vandeleur, C.L., Mohler-Kuo, M., Eichholzer, M., 2015. Associations between fruit and vegetable consumption and psychological distress: results from a population-based study. BMC Psychiatry 15, 213. 
Rienks, J., Dobson, A.J., Mishra, G.D., 2013. Mediterranean dietary pattern and prevalence and incidence of depressive symptoms in mid-aged women: results from a large community-based prospective study. Eur J Clin Nutr 67 (1), 75-82.

Ruusunen, A., Lehto, S.M., Mursu, J., Tolmunen, T., Tuomainen, T.P., Kauhanen, J., Voutilainen, S., 2014. Dietary patterns are associated with the prevalence of elevated depressive symptoms and the risk of getting a hospital discharge diagnosis of depression in middle-aged or older Finnish men. J Affect Disord 159, $1-6$.

Sanhueza, C., Ryan, L., Foxcroft, D.R., 2013. Diet and the risk of unipolar depression in adults: systematic review of cohort studies. J Hum Nutr Diet 26 (1), 56-70.

Schweizerische Gesellschaft für Ernährung SGE, 2013. Schweizer Lebensmittelpyramide. available: http://www.sge-ssn.ch/de/ich-und-du/essen-undtrinken/ausgewogen/lebensmittelpyramide/ . Last access 11.04.2016. .

Swiss Federal Statistical Office, Telefonischer und schriftlicher Fragebogen. Schweizerische Gesundheitsbefragung 2012 in Kürze: Konzept, Methode, Durchführung.

U.S. Department of Agriculture and U.S. Department of Health and Human Services, 2010. Dietary guidelines for Americans., 7 ed. U.S. Government Printing Office, Washington, DC.

WCRF, AICR, 2009. Policy and Action for Cancer Prevention. Food, Nutrition, and Physical Activity: a Global Perspective.

Whiteford, H.A., Degenhardt, L., Rehm, J., Baxter, A.J., Ferrari, A.J., Erskine, H.E., Charlson, F.J., Norman, R.E., Flaxman, A.D., Johns, N., Burstein, R., Murray, C.J., Vos, T., 2013. Global burden of disease attributable to mental and substance use disorders: findings from the Global Burden of Disease Study 2010. Lancet 382 (9904), 15751586.

World Health Organisation, 2004. Global strategy on diet, physical activity and health. 
Tab. 1: Characteristics of the participants stratified by presence or absence of major depressive disorder from the CoLaus/CoPsyColaus study and 2012 Swiss Health Survey

\begin{tabular}{|c|c|c|c|c|c|c|c|}
\hline \multicolumn{4}{|l|}{ CoLaus/PsyCoLaus } & \multicolumn{4}{|l|}{ Swiss Health Survey } \\
\hline \multicolumn{2}{|l|}{ Depression $^{1}$} & no & yes & Depression $^{1}$ & & no & yes \\
\hline \multirow{2}{*}{\multicolumn{2}{|c|}{$\mathrm{n}$}} & 1,977 & 1,643 & $\mathrm{n}$ & & 10,478 & 554.0 \\
\hline & & $\begin{array}{r}58.9 \\
(10.8)\end{array}$ & $55.5(9.7)$ & Age, mean (SD) & & $\begin{array}{r}57.7 \\
(0.17)\end{array}$ & $\begin{array}{r}53.5 \\
(0.59)\end{array}$ \\
\hline \multicolumn{2}{|l|}{ Sex, $\%$ men } & 54.3 & 34.0 & Sex, $\%$ men & & 50.1 & 44.7 \\
\hline \multicolumn{2}{|l|}{$\mathrm{SES}^{2}$, mean $(\mathrm{SD})$} & $\begin{array}{r}3.50 \\
(1.20)\end{array}$ & $\begin{array}{r}3.56 \\
(1.19)\end{array}$ & Educational level, $\%$ & Low & 12.0 & 19.2 \\
\hline \multirow{4}{*}{ Alcohol consumption } & & & & & Middle & 55.1 & 54.2 \\
\hline & & $\%$ & $\%$ & & High & 32.9 & 26.6 \\
\hline & Never & 21.8 & 25.1 & Alcohol consumption, $\%$ & $\begin{array}{l}\text { None or low consumption } \\
\text { Hazardous chronic }\end{array}$ & 95.3 & 95.4 \\
\hline & Low (1-13 drinks/week) & 60.8 & 63.4 & & consumption $^{2}$ & 4.7 & 4.6 \\
\hline \multirow{5}{*}{$\mathrm{BMI} \mathrm{kg} / \mathrm{m}^{2}$} & $\begin{array}{l}\text { Medium-high risk (14-34 } \\
\text { drinks/week) }\end{array}$ & 15.3 & 10.8 & & & & \\
\hline & Very high (35+ drinks/week) & 2.1 & 0.7 & & & $\%$ & $\%$ \\
\hline & $<18.5$ & 1.3 & 1.4 & BMI kg/m² & $<18.5$ & 2.3 & 2.5 \\
\hline & $\geq 18.5$ to $<25.0$ & 42.4 & 45.2 & & $\geq 18.5$ to $<25.0$ & 49.7 & 43.6 \\
\hline & $\geq 25.0$ to $<30.0$ & 39.6 & 37.0 & & $\geq 25.0$ to $<30.0$ & 36.4 & 32.1 \\
\hline \multirow{3}{*}{ Smoking history } & $\geq 30$ & 16.8 & 16.4 & & $\geq 30$ & 11.7 & 21.8 \\
\hline & Never & 42.8 & 38.9 & Smoking history & Never & 48.1 & 38.3 \\
\hline & Former smoker & 38.6 & 38.3 & & Former smoker & 28.3 & 26.7 \\
\hline \multirow{3}{*}{$\begin{array}{l}\text { Moderate physical } \\
\text { activity }\end{array}$} & Current smoker & 18.6 & 22.8 & & Current smoker & 23.7 & 35.0 \\
\hline & $\geq 20$ min twice a week & 74.7 & 72.6 & $\begin{array}{l}\text { Moderate physical } \\
\text { activity }\end{array}$ & $\geq 150$ min per week & 73.0 & 55.7 \\
\hline & $<20$ min twice a week & 25.3 & 27.5 & & $<150$ min per week & 27.0 & 44.3 \\
\hline \multicolumn{8}{|c|}{ Adherence to dietary recommendations: } \\
\hline \multirow{3}{*}{\multicolumn{2}{|c|}{$\begin{array}{l}\text { Fruit and/or fruit juice (at least two portions per day) } \\
\text { Vegetables/salad and/or vegetable juice (at least } 3 \text { portions per } \\
\text { day) } \\
\text { At least } 3 \text { portions of vegetables and } 2 \text { portions of fruit per day } \\
\text { (5-a-day) }\end{array}$}} & 46.7 & 49.4 & & & 38.8 & 35.2 \\
\hline & & 10.5 & 13.2 & & & 19.6 & 16.1 \\
\hline & & 7.1 & 9.7 & & & 12.7 & 9.8 \\
\hline \multicolumn{2}{|c|}{ Less than 5 portions of meat per week } & 51.9 & 54.8 & & & 64.6 & 67.0 \\
\hline
\end{tabular}


Less than 5 portions of red or processed meat per week At least 1 portion of fish per week

${ }^{2}$ socio-economic status. A value of 3 represents an SES of III (middle class) on the Hollingshead Scale
${ }^{1}$ Major depressive disorder measured by PHQ-9 and data weighted according the Swiss general population

$2>20 \mathrm{~g}$ ethanol daily for women, and $>40 \mathrm{~g}$ ethanol daily for men 
Tab. 2: Associations between healthy dietary intake and current depression (no vs. yes) in CoLaus/PsyCoLaus study and 2012 Swiss Health Survey

\begin{tabular}{|c|c|c|c|c|c|}
\hline & \multirow[t]{2}{*}{$\begin{array}{c}\text { No } \\
\text { depression }\end{array}$} & \multicolumn{2}{|c|}{$\begin{array}{c}\text { Depression }^{1} \\
\text { (CoLaus/PsyCoLaus) }\end{array}$} & \multicolumn{2}{|c|}{$\begin{array}{l}\text { Depression }^{2} \\
(2012 \mathrm{SHS})\end{array}$} \\
\hline & & OR & $95 \% \mathrm{CI}$ & OR & $95 \% \mathrm{CI}$ \\
\hline \multicolumn{6}{|c|}{ Fruit and/or fruit juice (at least two portions per day) } \\
\hline age and sex adjusted model & 1 & 1.14 & {$[0.86,1.51]$} & 0.88 & {$[0.69,1.11]$} \\
\hline multivariable adjusted model ${ }^{3}$ & 1 & 1.20 & {$[0.90,1.60]$} & 0.98 & {$[0.77,1.25]$} \\
\hline multivariable adjusted model plus diet ${ }^{4}$ & 1 & 1.14 & {$[0.87,1.54]$} & 1.00 & {$[0.78,1.28]$} \\
\hline \multicolumn{6}{|c|}{ Vegetables/salad and/or vegetable juice (at least 3 portions per day) } \\
\hline age and sex adjusted model & 1 & 1.44 & {$[0.97,2.12]$} & 0.66 & {$[0.49,0.88]$} \\
\hline multivariable adjusted model ${ }^{3}$ & 1 & 1.46 & {$[0.98,2.18]$} & 0.78 & {$[0.58,1.04]$} \\
\hline multivariable adjusted model plus diet ${ }^{5}$ & 1 & 1.41 & {$[0.94,2.13]$} & 0.76 & {$[0.56,1.04$} \\
\hline \multicolumn{6}{|c|}{ At least 3 portions of vegetables and 2 portions of fruit per day (5-a-day) } \\
\hline age and sex adjusted model & 1 & 1.54 & {$[0.99,2.39]$} & 0.69 & {$[0.48,0.98]$} \\
\hline multivariable adjusted model ${ }^{3}$ & 1 & 1.53 & {$[0.97,2.40]$} & 0.82 & {$[0.57,1.18]$} \\
\hline multivariable adjusted model plus diet ${ }^{6}$ & 1 & 1.52 & {$[0.96,2.40]$} & 0.80 & {$[0.56,1.16]$} \\
\hline \multicolumn{6}{|l|}{ Less than 5 portions of meat per week } \\
\hline age and sex adjusted model & 1 & 1.04 & {$[0.78,1.39]$} & 1.18 & {$[0.94,1.48]$} \\
\hline multivariable adjusted model ${ }^{3}$ & 1 & 1.05 & {$[0.78,1.41]$} & 1.21 & {$[0.96,1.53]$} \\
\hline multivariable adjusted model plus $\operatorname{diet}^{7}$ & 1 & 1.07 & {$[0.79,1.45]$} & 1.19 & {$[0.94,1.50]$} \\
\hline \multicolumn{6}{|c|}{ Less than 5 portions of red or processed meat per week } \\
\hline age and sex adjusted model & 1 & 1.01 & {$[0.73,1.41]$} & \multicolumn{2}{|c|}{ not applicable } \\
\hline multivariable adjusted model ${ }^{3}$ & 1 & 1.01 & {$[0.72,1.42]$} & & \\
\hline multivariable adjusted model plus $\operatorname{diet}^{8}$ & 1 & 1.09 & {$[0.77,1.54]$} & & \\
\hline \multicolumn{6}{|l|}{ At least 1 portion of fish per week } \\
\hline age and sex adjusted model & 1 & 1.02 & {$[0.73,1.43]$} & 1.26 & {$[0.99,1.58]$} \\
\hline multivariable adjusted model ${ }^{3}$ & 1 & 1.09 & {$[0.78,1.54]$} & 1.29 & {$[1.02,1.63]$} \\
\hline multivariable adjusted model plus $\operatorname{diet}^{9}$ & 1 & 1.05 & {$[0.74,1.50]$} & 1.28 & {$[1.01,1.63]$} \\
\hline
\end{tabular}

\footnotetext{
${ }^{1}$ Lifetime major depressive disorder measured by DIGS

${ }^{2}$ Major depressive disorder measured by PHQ-9 and data weighted according the Swiss general population

${ }^{3}$ Adjusted for age, sex, SES, alcohol consumption, BMI, smoking, physical activity

${ }^{4}$ Multivariable adjusted and additionally adjusted for vegetables, total meat and fish.

${ }^{5}$ Multivariable adjusted and additionally adjusted for fruit, total meat and fish.

${ }^{6}$ Multivariable adjusted and additionally adjusted for total meat and fish.

${ }^{7}$ Multivariable adjusted and additionally adjusted for fruit, vegetables and fish.

${ }^{8}$ Multivariable adjusted and additionally adjusted for fruit, vegetables, total meat minus red meat and fish.

${ }^{9}$ Multivariable adjusted and additionally adjusted for fruit, vegetables and total meat.
} 
Tab. 3: Associations between healthy dietary intake and subtypes of depression, multinomial logistic regression analysis; data from CoLaus/PsyCoLaus

\begin{tabular}{|c|c|c|c|c|c|c|c|c|c|c|c|c|c|c|c|c|c|}
\hline \multirow[t]{2}{*}{ Major depressive disorder } & \multirow[t]{2}{*}{$\begin{array}{c}\text { No } \\
(n=1977)\end{array}$} & \multicolumn{2}{|c|}{$\begin{array}{c}\text { Remitted } \\
\text { unspecified } \\
(n=635)\end{array}$} & \multicolumn{2}{|c|}{$\begin{array}{c}\text { Remitted combined } \\
(n=191)\end{array}$} & \multicolumn{2}{|c|}{$\begin{array}{c}\text { Remitted } \\
\text { melancholic } \\
(n=361)\end{array}$} & \multicolumn{2}{|c|}{$\begin{array}{l}\text { Remitted atypical } \\
(n=226)\end{array}$} & \multicolumn{2}{|c|}{$\begin{array}{c}\text { Current } \\
\text { unspecified }(n=75)\end{array}$} & \multicolumn{2}{|c|}{$\begin{array}{l}\text { Current combined } \\
(n=36)\end{array}$} & \multicolumn{2}{|c|}{$\begin{array}{c}\text { Current } \\
\text { melancholic } \\
(n=58)\end{array}$} & \multicolumn{2}{|c|}{$\begin{array}{l}\text { Current atypical } \\
\quad(n=61)\end{array}$} \\
\hline & & OR & $95 \% \mathrm{CI}$ & OR & $95 \% \mathrm{CI}$ & OR & $95 \% \mathrm{CI}$ & OR & $95 \% \mathrm{CI}$ & $\mathrm{OR}$ & $95 \%$ CI & OR & $95 \% \mathrm{CI}$ & OR & $95 \% \mathrm{CI}$ & OR & $95 \% \mathrm{CI}$ \\
\hline \multicolumn{18}{|c|}{ Fruit and/or fruit juice (at least two portions per day) } \\
\hline age and sex adjusted model & 1 & 1.03 & {$[0.86,1.24]$} & 0.92 & {$[0.68,1.24]$} & 1.16 & {$[0.92,1.46]$} & 1.05 & {$[0.79,1.39]$} & 1.10 & {$[0.69,1.76]$} & 1.51 & {$[0.77,2.96]$} & 1.28 & {$[0.75,2.17]$} & 0.90 & {$[0.54,1.51]$} \\
\hline multivariable adjusted model $^{1}$ & 1 & 1.02 & {$[0.85,1.23]$} & 0.96 & {$[0.70,1.31]$} & 1.19 & {$[0.94,1.50]$} & 1.04 & {$[0.78,1.38]$} & 1.16 & {$[0.72,1.87]$} & 1.55 & {$[0.78,3.07]$} & 1.42 & {$[0.83,2.44]$} & 0.98 & {$[0.58,1.66]$} \\
\hline $\begin{array}{l}\text { multivariable adjusted model } \\
\text { plus diet }^{2}\end{array}$ & 1 & 1.03 & {$[0.85,1.24]$} & 0.95 & {$[0.69,1.30]$} & 1.22 & {$[0.96,1.55]$} & 1.05 & {$[0.79,1.41]$} & 1.07 & {$[0.66,1.75]$} & 1.65 & {$[0.82,3.33]$} & 1.20 & {$[0.69,2.11]$} & 1.00 & {$[0.58,1.71]$} \\
\hline \multicolumn{18}{|c|}{ Vegetables/salad and/or vegetable juice (at least 3 portions per day) } \\
\hline age and sex adjusted model & 1 & 1.13 & {$[0.85,1.49]$} & 1.34 & {$[0.88,2.05]$} & 0.95 & {$[0.66,1.36]$} & 1.07 & {$[0.70,1.63]$} & 1.86 & {$[1.03,3.35]$} & 0.89 & {$[0.31,2.55]$} & 2.37 & {$[1.27,4.44]$} & 0.62 & {$[0.25,1.58]$} \\
\hline multivariable adjusted model $^{1}$ & 1 & 1.14 & {$[0.86,1.51]$} & 1.34 & {$[0.87,2.05]$} & 0.95 & {$[0.66,1.38]$} & 1.05 & {$[0.68,1.60]$} & 1.82 & {$[1.00,3.29]$} & 0.85 & {$[0.29,2.45]$} & 2.54 & {$[1.35,4.79]$} & 0.63 & {$[0.25,1.61]$} \\
\hline $\begin{array}{l}\text { multivariable adjusted model } \\
\text { plus diet }^{3}\end{array}$ & 1 & 1.15 & {$[0.87,1.54]$} & 1.41 & {$[0.91,2.19]$} & 0.94 & {$[0.65,1.36]$} & 1.05 & {$[0.68,1.62]$} & 1.77 & {$[0.96,3.25]$} & 0.74 & {$[0.25,2.16]$} & 2.44 & {$[1.27,4.70]$} & 0.68 & {$[0.24,1.63]$} \\
\hline \multicolumn{18}{|c|}{ At least 3 portions of vegetables and 2 portions of fruit per day (5-a-day) } \\
\hline age and sex adjusted model & 1 & 1.06 & {$[0.75,1.48]$} & 1.41 & {$[0.86,2.29]$} & 1.15 & {$[0.77,1.73]$} & 1.23 & {$[0.77,1.98]$} & 2.13 & {$[1.11,4.07]$} & 0.97 & {$[0.29,3.22]$} & 2.35 & {$[1.15,4.80]$} & 0.72 & {$[0.26,2.03]$} \\
\hline multivariable adjusted model $^{1}$ & 1 & 1.07 & {$[0.76,1.50]$} & 1.41 & {$[0.86,2.31]$} & 1.18 & {$[0.79,1.77]$} & 1.22 & {$[0.76,1.97]$} & 2.12 & {$[1.10,4.08]$} & 0.90 & {$[0.27,3.03]$} & 2.54 & {$[1.23,5.22]$} & 0.73 & {$[0.26,2.06]$} \\
\hline $\begin{array}{l}\text { multivariable adjusted model } \\
\text { plus } \operatorname{diet}^{4}\end{array}$ & 1 & 1.10 & {$[0.78,1.54]$} & 1.49 & {$[0.91,2.44]$} & 1.22 & {$[0.81,1.84]$} & 1.25 & {$[0.77,2.02]$} & 2.09 & {$[1.08,4.06]$} & 0.90 & {$[0.27,3.05]$} & 2.51 & {$[1.21,5.21]$} & 0.71 & {$[0.25,2.03]$} \\
\hline \multicolumn{18}{|c|}{ Less than 5 portions of meat per week } \\
\hline age and sex adjusted model & 1 & 1.06 & {$[0.88,1.28]$} & 1.19 & {$[0.87,1.63]$} & 1.15 & {$[0.91,1.45]$} & 0.90 & {$[0.68,1.20]$} & 0.8 & {$[0.49,1.27]$} & 0.68 & {$[0.35,1.35]$} & 1.52 & {$[0.88,2.64]$} & 1.29 & {$[0.75,2.21]$} \\
\hline multivariable adjusted model $^{1}$ & 1 & 1.04 & {$[0.86,1.25]$} & 1.20 & {$[0.87,1.65]$} & 1.14 & {$[0.90,1.45]$} & 0.92 & {$[0.69,1.23]$} & 0.8 & {$[0.51,1.34]$} & 0.70 & {$[0.35,1.39]$} & 1.47 & {$[0.84,2.58]$} & 1.30 & {$[0.75,2.24]$} \\
\hline
\end{tabular}




\section{Less than 5 portions of red or processed meat per week}

age and sex adjusted model

multivariable adjusted model ${ }^{1}$

$1.10[0.89,1.35] \quad 1.24 \quad[0.86,1.79]$

$1.28 \quad[0.97,1.68]$

$1.00 \quad[0.73,1.39]$

$1 \quad[0.61,1.79]$

$1.28 \quad[0.97,1.69]$

$1.02[0.73,1.41]$

$1.09 \quad[0.63,1.90]$

$1.26[0.95,1.68]$

$1.03 \quad[0.74,1.44]$

$1.22[0.69,2.15]$

plus $\operatorname{diet}^{6}$

$\begin{array}{lllll}1 & 1.04 & {[0.84,1.29]} & 1.22 & {[0.84,1.78}\end{array}$

$0.86 \quad[0.66,1.11]$

$0.90 \quad[0.65,1.24]$

$1.04[0.60,1.81]$

$0.84 \quad[0.64,1.09]$

$0.86 \quad[0.62,1.19]$

$1.06 \quad[0.61,1.86]$

$0.83[0.63,1.09] \quad 0.83 \quad[0.59,1.16]$

$0.98 \quad[0.55,1.73]$

multivariable adjusted mode plus diet

$0.67[0.33,1.38]$

$1.2[0.62,2.17]$

$1.3[0.66,2.44]$

$0.68 \quad[0.33,1.41]$

$1.12 \quad[0.59,2.10]$

$1.30 \quad[0.68,2.52]$

$0.68 \quad[0.32,1.42]$

$1.16 \quad[0.61,2.21] \quad 1.28 \quad[0.65,2.51]$

${ }^{1}$ Adjusted for age, sex, SES, alcohol consumption, BMI, smoking, physical activity

${ }^{2}$ Multivariable adjusted and additionally adjusted for vegetables, total meat and fish.

${ }^{3}$ Multivariable adjusted and additionally adjusted for fruit, total meat and fish.

${ }^{4}$ Multivariable adjusted and additionally adjusted for total meat and fish.

${ }^{5}$ Multivariable adjusted and additionally adjusted for fruit, vegetables and fish.

${ }^{6}$ Multivariable adjusted and additionally adjusted for fruit, vegetables, total meat minus read meat and fish.

${ }^{7}$ Multivariable adjusted and additionally adjusted for fruit, vegetables and total meat. 